\title{
LA ADMINISTRACIÓN DIOCESANA COMO INSTRUMENTO DE EQUIPAMIENTO ECLESIÁSTICO DEL TERRITORIO. ÁNGEL MARIANO MOSCOSO, CÓRDOBA DEL TUCUMÁN (1788-1804)
}

\author{
The diocesan government as a tool for the territorial ecclesiastical equipment. \\ Angel Mariano Moscoso, Cordoba del Tucuman (1788-1804)
}

Mazzoni, María Laura*

\section{Resumen}

El trabajo propone el análisis de la administración diocesana de Ángel Mariano Moscoso -obispo del Tucumán de 1788 a 1804- como una puerta de entrada al estudio de aspectos cotidianos del proceso de control social. En este sentido, la gestión episcopal de este prelado nos permite observar los mecanismos por los cuales se reforzaba la presencia eclesiástica a través del equipamiento eclesiástico del territorio. Por otro lado, estudiamos las visitas diocesanas llevadas a cabo durante la administración de Moscoso como un instrumento del ejercicio de gobierno. La mayoría de las fuentes utilizadas para este artículo corresponden a fondos del Archivo del Arzobispado de Córdoba (AAC) que fueron cotejados o complementados con otros fondos documentales cuando fue necesario.

$<$ Administración diocesana $><$ Equipamiento eclesiástico del territorio $><$ Ángel Mariano Moscoso $>$ $<$ Obispado del Tucumán $>$

\begin{abstract}
This article deals with the analysis of the diocesan administration of Angel Mariano Moscoso -bishop of Tucuman from 1788 to 1804- as an excuse to study domestic aspects of the process of social control. Hence, the episcopal government of this prelate allows us to observe the mechanisms by which the presence of the church in this diocese was reinforced through the ecclesiastical equipment of the territory. Besides, we have studied the diocesan visits performed by Moscoso as a tool of government. Most of the documents analyzed in this article belong to the Archivo del Arzobispado de Córdoba (AAC), complemented by documents from other Archives when it was necessary.
\end{abstract}

$<$ Diocesan administration $><$ ecclesiastical equipment of the territory $><$ Angel Mariano Moscoso $>$

$<$ Bishopric of Tucuman $>$

Recibido: 10/11/2014 // Aceptado: 04/06/2015

\footnotetext{
* Dra. en Historia. Becaria Posdoctoral. CONICET-Inst. Ravignani. Ayudante de Primera en Historia Económica y Social-FCSyE-UNMdP.
} 
Mazzoni. La administración diocesana como instrumento de equipamiento eclesiástico del territorio...

\section{Introducción}

Ángel Mariano Moscoso se convirtió en obispo de la diócesis de Córdoba del Tucumán en 1788. Elegido prelado en la mitra tucumana por una Real Cédula firmada en San Lorenzo del Escorial el 27 de octubre de 1787, fue confirmado por la Santa Sede el 10 de marzo de 1788, y ocupó hasta su muerte en 1804 el cargo que había dejado vacante Joseph Antonio de San Alberto.

$\mathrm{Su}$ gestión episcopal nos permite observar una serie de aspectos vinculados al control social en el periodo tardocolonial, a través, principalmente, del análisis de las visitas celebradas en la jurisdicción diocesana. El obispo constituía entonces, junto al alto clero local, el estamento letrado de la sociedad colonial, y por lo tanto, detentaba un capital simbólico (Bourdieu, 1985) que lo posicionaba en un lugar de primacía en el espacio tucumano.

El presente trabajo se basa en el análisis de la administración de gobierno de este prelado originario del Alto Perú. Nos centraremos en los autos emitidos a partir de las visitas que celebró en la diócesis. Estos edictos nos permiten observar cuestiones particulares de su gestión episcopal en el periodo, y a través de ellos conocer aspectos relacionados al ejercicio de gobierno y al control social de la jerarquía eclesiástica.

Gran parte de las visitas canónicas y sus autos se encuentran alojadas en el Fondo Visitas del Archivo del Arzobispado de Córdoba (AAC). Cuando fue necesario, complementamos esta documentación con fuentes del Archivo General de Indias (AGI).

\section{La formación de Moscoso}

El nuevo prelado provenía del clero secular, aunque había sido formado en la Universidad del Cuzco, administrada por la Compañía de Jesús hasta su expulsión de América. Sus padres, Petronila Pérez de Oblitas y Gaspar José Moscoso Zegarra, pertenecían a la rica y poderosa elite arequipeña. Su padre había ocupado el cargo de alcalde en esa jurisdicción del Virreinato peruano.

Moscoso pertenecía a un linaje de obispos: Juan Manuel Moscoso y Peralta, prelado del Tucumán entre 1770 a 1778, y luego del Cuzco, era tío de Ángel Mariano (Moyano, 1893: 565); otro de sus tíos, Fernando Pérez de Oblitas, lo era en Santa Cruz de la Sierra cuando Moscoso se ordenó sacerdote, y en 1757 lo nombró secretario de cámara, le confirió el sacerdocio ese mismo año, y lo constituyó, el 28 de julio de 1758, en provisor y vicario general del obispado. ${ }^{1}$

Creemos que el origen del obispo Ángel Mariano Moscoso es un aspecto importante a considerar, ya que su elección estuvo relacionada con una experiencia previa que vinculaba a los clérigos arequipeños con la zona meridional de los territorios españoles (Mazzoni, 2013). Arequipa era un destino y un origen usual para la trayectoria eclesiástica de los prelados que ocupaban la silla tucumana. Juan Manuel Moscoso y Peralta fue nombrado prelado en 1770 y ocupó la silla episcopal hasta 1778. Él

\footnotetext{
Archivo General de Indias (AGI en adelante), Buenos Aires 602, (1701-1808) Consultas y provisiones
} eclesiásticas del Tucumán, Córdoba 6/8/1787. 
también provenía de Arequipa, donde se desempeñaba como obispo auxiliar cuando fue nombrado para la diócesis tucumana. ${ }^{2}$ Su antecesor, Fray Manuel Abad Illana, a cargo de la mitra del Tucumán desde 1763 a 1770, si bien era de origen vallisoletano, sería nombrado luego en Arequipa. ${ }^{3}$

En este sentido, Ángel Mariano Moscoso también tuvo una destacada participación al servicio de la Corona en 1780, cuando estalló la rebelión de Tupac Amaru en el Alto Perú. El futuro obispo se desempeñaba como párroco de Tarata, y existen referencias que informan que "en Tarata, el sacerdote Mariano Moscoso, donó fondos para mejorar las tropas realistas" (Robins, 2009: 168). Juan Manuel Moscoso y Peralta, obispo del Cuzco en ese momento, organizó allí la recolección de fondos y la formación de milicias para aplacar la rebelión y defender la plaza cuzqueña (Aparicio O. de M., 2000). Las milicias incluían al clero, que hacía sus ejercicios militares en el Palacio Episcopal bajo la supervisión del propio obispo (Aparicio O. de M., 2000: 11).

Al respecto, se ha sostenido que su actuación como mediador en el conflicto llegó a acompañar al Ejército Real encargado de sofocar los levantamientos de 1780 en la zona altoperuana- le valió el reconocimiento del rey:

"Este gran servicio prestado oportunamente, fue notado por la Real Audiencia y Cabildo secular de Charcas, cuyas autoridades dieron de él cuenta a S. M., quien como premio despachó dos órdenes para la Cámara de Indias, en las que disponía consultasen al señor Moscoso sobre prebendas de la Iglesia de Charcas" (Moyano, 1893, I: 567).

No es de extrañar que su nombre familiar $-\mathrm{y}$ su capacidad para mediar en situaciones problemáticas- influyera en la elección de un candidato cuya trayectoria como párroco y secretario de cámara no tenía de por sí méritos suficientes para la obtención de un obispado.

\section{Control diocesano a través de la visita}

Moscoso se caracterizó por ser un obispo "en movimiento"; recorrió toda la diócesis para cumplir con la tarea de visitarla, en persona, o a través de visitadores. De hecho, fue el propio prelado quien después de una visita que había durado casi tres años advertía la vasta extensión del territorio, que le dificultaba la comunicación con sus párrocos.

Por otro lado, expresaba otra de las limitaciones con las que se topaba en la administración de su diócesis: no sólo debía encargarse de un territorio demasiado grande, sino que carecía además de hombres experimentados en el gobierno episcopal. La inexistencia de sínodos provinciales desde hacía tanto tiempo había forjado una

\footnotetext{
AGI, Buenos Aires, 602.
}

3 AGI, Buenos Aires, 602. 
Mazzoni. La administración diocesana como instrumento de equipamiento eclesiástico del territorio...

administración diocesana que se regía por fuentes canónico-jurídicas múltiples y que dependía de la presencia y el apuntalamiento del obispo, cuando lo había, como única referencia (Mazzoni, 2015). El prelado representaba aquí la ley y la jurisdicción, y por eso Moscoso advertía que "un obispo del Tucumán se ve en la dura necesidad de obrar por sí solo, sin que antecedan las luces experimentales de los conductores subalternos, a cuyos ojos deben ser mas patentes las necesidades". ${ }^{4}$

En este sentido, la visita canónica era una de las obligaciones de los obispos (Martini, 1997: 267). El objetivo de esta tarea era constatar el estado material de iglesias y cementerios, y el control del cumplimiento del precepto anual entre otras prácticas religiosas de la feligresía. Como resultado de cada visita, el obispo o el visitador en el que había delegado la tarea redactaba un informe que observaba el estado de la parroquia y los testimonios de los entrevistados. Además, la visita arrojaba en ocasiones los autos. Durante el ejercicio de gobierno de una diócesis se producían, como en las funciones del gobierno civil, una serie de autos, que eran decretos judiciales dados en alguna causa, y que tenían que ver directamente con el derecho canónico local. Muchos de los edictos que encontramos en los archivos corresponden a decretos que en gran medida tienden a la modificación de las costumbres (Martínez de Sánchez, 2008).

Dada la vasta extensión del territorio y las magras rentas de algunos beneficios eclesiásticos como el tucumano, con frecuencia los obispos no cumplían con esta obligación -o no completamente-y las visitas solían ser escasas en algunos espacios.

Sin embargo, durante el gobierno de Moscoso se practicaron más visitas que durante otras gestiones episcopales anteriores y posteriores. Si bien el obispo San Alberto, su antecesor, estuvo en visita en varias ocasiones, la tarea pastoral del prelado arequipeño en este sentido supera al resto de las experiencias episcopales en términos absolutos. En el caso de Orellana y Lascano, los obispos que lo sucedieron, la escasa cantidad de visitas realizadas a los curatos de la diócesis estuvo relacionada con el contexto de guerra y reformas que abrió el proceso revolucionario iniciado en 1810 en el territorio.

En parte esto se explica porque tuvo un prolongado gobierno: su mitrado duró 16 años, mientras que San Alberto sólo ocupó la silla durante cuatro (los dos primeros años de su mandato se encontraba en la península). Pero este gobierno "en movimiento" que Moscoso llevó a cabo no se debió solamente a sus largos años de gestión episcopal, sino que también estuvo relacionado con una manera de entender la tarea pastoral. En sus años de gobierno, visitó personalmente la diócesis la mayoría de las veces; en pocas ocasiones delegó la tarea.

Sobre este asunto, el propio Moscoso informaba: "tengo el consuelo de haberla concluido por mí mismo, a excepción de los partidos de Catamarca, y Rioja y algunos pocos curatos, a que he destinado sujetos de mi entera confianza" (Bruno, 1970: 489).

Cuando nombró visitadores para cumplir con esta obligación, las personas en las que el prelado delegó las visitas eran de su entera confianza. Así ocurrió en el caso de los

\footnotetext{
${ }^{4}$ Archivo del Arzobispado de Córdoba (AAC en adelante), Leg. 30, t. I, Colección de papeles de Funes,
} citado por: Bruno 1970, VI: 474. 
curatos de Pocho y San Javier, donde asignó esta tarea pastoral a Miguel de Castro, cura y vicario de Punilla, que fue acompañado por el Notario de visita Gaspar Trucios. ${ }^{5}$ Esto es importante, ya que la visita podía arrojar resultados que exigieran la intervención del obispo, y en ese caso, ayudaba haberla delegado en alguien de su círculo de confianza. Si los informes que el visitador elevaba al obispo constataban un mal desempeño del sacerdote del curato, el prelado podía intervenir la parroquia, destituyendo al sacerdote en cuestión, y nombrando a cargo de ese curato a otro clérigo.

Tomemos por caso la visita a San Javier, donde el prelado recibió diferentes denuncias contra su párroco, Jose Agustin Albares. Según algunos de sus feligreses, Albares no daba misa asiduamente en los templos alejados de San Javier. Además, había dejado morir a una parroquiana sin recibir el sacramento de la extremaunción, no contaba con ayudante para hacer frente a las tareas sacerdotales de este extenso curato, y había muchas personas dentro de su parroquia que no cumplían con el precepto anual por estar enemistados con el sacerdote. En estas circunstancias, y luego de interrogar a algunos vecinos notables de la parroquia y al propio párroco, Moscoso resolvía alejar a Alvares de su parroquia "haciendose por lo expuesto perjudicial su residencia en aquel beneficio" y ordenaba "[...] que en el termino de doce días los primeros y siguientes al de la notificacion de este Auto comparesca en esta nuestra Audiencia Episcopal". ${ }^{6} \mathrm{Al}$ deponer de su cargo al cura Albares, Moscoso colocó en la parroquia precisamente a uno de los dos funcionarios que habían llevado a cabo la visita en su nombre:

"Y siendo preciso nombrar un Eclesiastico que en calidad de Excusador atienda a aquel Curato pase à servirlo el Ministro Don Gaspar Trucios, librándosele al efecto titulo en forma con la petision de contribuir ciento cinquenta pesos en cada año al expresado Doctor Albarez, y se mantenga indefectiblemente un Ayudante colocado a proporcionada distancia de la capilla Parroquial [...] asignando como asignamos para este Ministerio à Don Hermenegildo Arias, ordenado a titulo de Teniente de Cura, y que ha estado sirviendo en calidad de tal al cura de los Anexos [...]"'

En los autos de Moscoso se nota la meticulosidad con la que llevó adelante las visitas. En la que realizó a Totoral, observaba el poco cuidado que se había tenido con los libros parroquiales y daba instrucciones exhaustivas de cómo redactarlos y cuidarlos correctamente. ${ }^{8}$ Sobre el cuidado del libro de bautismo, el obispo advertía "que este libro se halla sin forros, y expuesto a romperse con el uso [...] que el cura y Vicario Interino Ministro Don Santiago Moreno ebite en adelante tan capitales defectos que a mas de debilitar la fe publica de este libro se oponen al arreglo y formalidad con que

\footnotetext{
AAC, Leg. 17, Visitas Canónicas, f. 1v, 2-1-1803.

6 AAC, Leg. 17, T. I, f. 25r, 20/04/1803.

7 AAC, Leg. 17, T. I, f. 25r, 20/04/1803.

8 AAC, Leg. 17, $417 \mathrm{v}-420 \mathrm{v}$.
} 
Mazzoni. La administración diocesana como instrumento de equipamiento eclesiástico del territorio...

debe llebarse atendida la importancia de su materia [...]". ${ }^{9}$ En Rio Segundo, el obispo observaba que:

"[...] además de carecer todos estos libros de foliacion, estan muchos sin forro. Que las fechas se ponen en numeros y sin el orden, y sequela natural de meses, y años, con otros muchísimos defectos, que hacen acreedor de un severo castigo al actual Cura Ministro Don Martin Olmos, por el descuido, negligencia y abandono, con que ha mirado este importante oficio de su Ministerio, haziendose mas reparables estas faltas de un cura, que es de los mas antiguos del Obispado, y que por lo mismo devia estar mas instruido en esta tan importante obligación $[\ldots]^{\prime \prime 10}$

El cuidado de la fábrica de las iglesias parroquiales es otro de los temas que se controlaban en la visita y al que los obispos le daban mucha importancia. Los templos, en tanto lugares sagrados de culto, debían estar en buen estado, y los sacerdotes debían cuidar el aseo y sus ornamentos. En la visita de Pocho, por ejemplo, Moscoso subrayaba el buen desempeño del sacerdote, ya que se había encargado de reparar las capillas de la parroquia y "hace que los derechos de sus fabricas no se disipen, sino que se inviertan en su culto y aseo". ${ }^{11}$ Por el contrario, en el curato de San Javier, el visitador encontraba una falta total de aseo, arreglo del templo, y la Capilla de las Talas "no tiene serradura la puerta, por cuia causa se entran las cabras hasta el altar, y lo ensucian". ${ }^{12}$

Los autos que Moscoso redactó durante su gobierno versaban en torno a muy variadas cuestiones. El obispo redactó estos edictos para regular temas como la forma en que debía administrarse el sacramento de la penitencia, las obligaciones del clero y de sus tenientes, la cobranza y el pago de diezmos, la exacción de la cuarta funeral, cómo debían explicar los sacerdotes la doctrina cristiana, y el hábito clerical, entre otras medidas. $^{13}$

Así, por ejemplo, su auto "Sobre el modo como deben manejarse los curas en las causas de concubinato" tiene que ver con la pervivencia de esta práctica en el obispado:

"[...] compete a los curas y vicarios, que con aquella circunspeccion, prudencia y afabilidad propias de su carácter, y ministerio caritativa y amorosamente amonesten a sus feligreses que les conste viven en ilícita amistad a que se aparten de ella

\footnotetext{
9 AAC, Leg. 17, 417 r-v.

${ }^{10}$ AAC, Leg. 17, Visita los Libros de Bautismos, Entierros y Casamientos de Españoles y Naturales del Curato de Rio Segundo.

${ }^{11}$ AAC, Leg. 17, t. I, 21/01/1803.

${ }^{12}$ AAC, Leg. 17, t. I, 09/02/1803.

${ }^{13} \mathrm{AAC}$, Autos y ordenes generales (1782-1859).
} 
para evitar el peligroso estado de sus conciencias, y la ruina, que con su escandalo causan en lo restante del Pueblo". ${ }^{14}$

Los informes del prelado cubrían temas como la reverencia que los fieles debían mostrar al entrar a los templos. Esto implicaba la prohibición de entrar con sombrero o birrete blanco, de comer o dormir en la iglesia y de hablar "ni con los propios parientes". ${ }^{15}$ Por otra parte, los excesos de la feligresía en los días festivos generaba la necesidad de una normativa que los sancionara. En San Salvador de Jujuy el obispo reglamentó bajo pena de multa de seis pesos "que de aquí en adelante no se habran las dichas pulperías, o tabernas, en que se expende el aguardiente ni se venda la chicha en puesto alguno", porque justamente esas ocasiones eran propicias para "entregarse a la embriaguez, y a los desordenes consiguientes a este vicio capital $[\ldots]$ ". ${ }^{16}$

La visita oficiaba así como un instrumento de control social. La gestión episcopal implicaba, en este sentido, la vigilancia y regulación de las prácticas de la feligresía, y la condena para los que osaban desafiar las normas; una condena que era, por un lado, una sanción canónica, y por el otro, una moral, que distinguía y estigmatizaba del resto de los fieles a la oveja descarriada. Esta era una función que los prelados compartían con otros actores sociales, como los jueces pedáneos en la campaña.

\section{Equipamiento eclesiástico del territorio}

La administración diocesana encerraba otro aspecto del gobierno de la diócesis que se relacionaba con la creación u oficialización de nuevas parroquias u oratorios para ampliar la estructura eclesiástica del obispado y formar así una red de parroquias más densa. Esto implicaba, muchas veces, confirmar u oficializar ciertas capillas u oratorios privados, que en la práctica funcionaban como públicos. Esto formaba parte de un proceso que podríamos definir como equipamiento eclesiástico del territorio allí donde la presencia de la Iglesia era más débil.

La efectiva corporización o materialización del espacio sagrado a través de la creación de curatos y la implantación de parroquias, capillas, o la confirmación de oratorios que funcionaban de hecho, formaba parte de lo que Darío Barriera reconoce como equipamiento político del territorio. Este proceso tenía una importancia crucial debido a la acentuación puesta por la iglesia católica en una marcada presencia territorial, ya que la tarea pastoral se llevaba a cabo a través de los templos y parroquias mayoritariamente. ${ }^{17}$ Barriera estudió a los alcaldes mayores de la villa de Santa Fe como

\footnotetext{
${ }^{14}$ AAC, Autos y ordenes generales (1782-1859), Córdoba, 20-07-1795.

${ }^{15}$ AAC, Autos y ordenes generales (1782-1859), Salta, 7-3-1792.

${ }^{16}$ AAC, Autos y ordenes generales (1782-1859), Salta, 26-11-1791.

${ }^{17}$ Una de las ideas-guía impuestas por el Concilio de Trento había sido la fuerte impronta parroquial que se debía dar a la Iglesia reformada. La vida religiosa en las comunidades católicas debía estar centrada en la parroquia. Ejemplo de esto es la prohibición expresa en los puntos del Concilio de celebrar misas en casa particulares. Para un estudio más detallado sobre la reforma de Trento en la iglesia ver: Di Stefano y Zanatta, 2009.
} 
Mazzoni. La administración diocesana como instrumento de equipamiento eclesiástico del territorio...

la presencia física permanente de la institución judicial/policial, pero sostiene que "no todo estaba en manos del cabildo: la instalación de parroquias y la creación de curatos también proporcionaron puntos de referencia para localizar población dispersa en el campo" (Barriera, 2010: 37).

Por ejemplo, en 1792, Moscoso visitaba los libros de bautismo, entierro y fábrica del oratorio de la hacienda del Totoral perteneciente a Antonio de la Quintana y confirmaba la licencia para que funcionara como un oratorio público. ${ }^{18}$ Las medidas tomadas por el obispo en sus autos de visita apuntaban a hacer efectivo el equipamiento de una estructura eclesiástica dispersa en la diócesis.

Precisamente, uno de los autos de 1792 se preocupaba de regular la actuación de los sacerdotes, y de que su trabajo pastoral se circunscribiera a los lugares sagrados -las iglesias y capillas- para imponerle un cariz legítimo a la práctica sacerdotal. En Salta, Moscoso informaba que había notado "muchos abusos con notable peligro de las conciencias" haciendo referencia al sacramento de la penitencia, y ordenaba:

"que en adelante ningún sacerdote pueda administrar este sacramento a ninguna persona de ambos sexos en casas particulares, sino que precisamente ha de ser en la Iglesia en otro lugar santo y religioso anejo a la misma Iglesia [...] que asimismo no puedan confesar mujeres en escaños, sillas y otros asientos, que no tengan separación entre el confesor, y la confesada [...] desde el amanecer hasta el punto de las oraciones, en que concluye el dia $[\ldots] " 19$

Determinar cuáles eran los lugares sagrados y convertirlos en los únicos espacios donde - a través del sacerdote- se podía tener contacto con los rituales del culto significaba demarcar el territorio sagrado y diferenciarlo del que no lo era, consagrarlo. La presencia de estas capillas u oratorios modificaba de alguna manera el lugar donde se asentaban. A través de ellos, refiere William Christian, "el mundo sagrado estaba permanentemente presente en el paisaje" (Christian, 1991: 153).

En este sentido, algunas medidas del obispo Moscoso deben interpretarse como un intento por reforzar la presencia y sociabilidad en los templos, sobre todo en la campaña del obispado. La diferencia entre la sede episcopal o parroquias matrices y la campaña, con respecto a la materialidad de la estructura eclesiástica, había sido expresada por el obispo arequipeño durante una visita:

"En el curso de mi visita he observado que si la fe ortodoxa en las capitales mantiene su pureza a beneficio de las frecuentes exhortaciones, en la campaña se halla mexclada con mil er-

\footnotetext{
${ }^{18}$ AAC, Leg. 17, 417 r-v.

${ }^{19}$ AAC, Autos y ordenes generales (1782-1859), Salta, 23-03-1792.
} 
rores; y, entre los indios neófitos, camina con la más escandalosa lentitud. El dilatado espacio de casi un siglo no ha bastado para que algunas reducciones hayan podido ser iniciadas en los misterios de la religión" 20

En las matrices, "las frecuentes exhortaciones" se hacían tangibles; materializaban el espacio sagrado, a partir de la presencia de templos de diversas órdenes regulares, la catedral, los monasterios, y otras capillas, y de los clérigos que impartían sermones. Pero esto no ocurría en las zonas rurales y en los pueblos de indios. En estas zonas el paisaje era diferente. La iglesia no tenía una presencia material tan marcada como la que se observaba en el ejido urbano. ${ }^{21}$ Allí, las capillas y oratorios estaban dispersos. En algunos parajes sólo había un oratorio privado que era ofrecido por su dueño para la celebración de la liturgia.

El cura párroco residía en la matriz del curato, y la poca frecuencia con la que accedía a pueblos alejados para celebrar el culto lo convertía en un actor ajeno a la comunidad. En la visita al curato de San Javier de 1803 puede observarse esta situación. El cura Juan Agustin Albares vivía en la matriz de San Javier, una parroquia de grandes dimensiones territoriales; su presencia en el resto de los templos era poco frecuente.

Cuando se realizó la visita a este curato, los indios de Nono presentaron un memorial al visitador por el cual explicaban el problema que tenían para reconstruir la iglesia del pueblo que Albares les había mandado cerrar "por su estado ruinoso", y su urgencia para reconstruirla ya que hacía seis meses se hallaban sin "el beneficio espiritual de la misa". El conflicto se había iniciado cuando Albares les ordenó a los pobladores de Nono que construyeran la iglesia en un lugar distinto al que había estado asentado el antiguo templo en ruinas, en las orillas del pueblo. Los indios pedían entonces, a través del Memorial, autorización para reconstruirla donde convenía a la gente del pueblo -en el lugar del antiguo asentamiento-. La resolución del visitador era favorable a esta petición:

"Respecto à que la redificacion de la Capilla de Nono se haze a expensas de los indios tributarios del Pueblo, quienes consultando con la mejor proporcion y comodidad para ser doctrinados pretenden hacerla en el mismo lugar que sirve de Pueblo como representan en su memorial; el Cura doctrinero Doctor Don Jose Agustin Albares no embaraze a los indios el que la trabajen en el sitio que quieren"22

\footnotetext{
${ }^{20}$ Citado por Cayetano Bruno en: Bruno, 1970: 474.

${ }^{21}$ Sobre este aspecto pueden consultarse los trabajos de María Elena Barral para el caso de la campaña bonaerense en el mismo periodo. Ver: Barral y Fradkin, 2007; Barral, 2005.

${ }^{22}$ AAC, Leg. 17, T. I, f. 17 v. y r., 03/02/1803.
} 
Mazzoni. La administración diocesana como instrumento de equipamiento eclesiástico del territorio...

Por otro lado, la presencia eclesiástica también estaba relacionada con la figura del sacerdote, y su buen desempeño en la tareas pastorales, "un equipamiento del territorio más refinado no siempre tiene que ver con distancia, extensión y número de hombres, sino con la manera en la que se dan las relaciones entre estos factores" (Barriera, 2010: 60).

Es por ellos que, como resultado de la visita al curato de San Javier, Moscoso recalcaba la necesidad de un ayudante de cura, allí donde el sacerdote no residía permanentemente. El ayudante se erigía como un "mojón", una marca de la presencia eclesiástica en las zonas alejadas. En el caso de San Javier, el obispo juzgó a Albares en la Audiencia Episcopal por su conducta. Este fue "recombenido porque no ha tenido Ayudante fixo en su curato, conceptuando ser necesario por su longitud y dispersión de sus feligreses $[\ldots] " .{ }^{23}$

El cobro de diezmos, en este sentido, y la acción misma de recaudarlos, portaba un simbolismo. Si el obispo era la cabeza de la Iglesia, y el cura su representante en la parroquia, era a ellos a quienes los fieles debían entregar parte del producto de su trabajo. El diezmo funcionaba así como un signo más de la presencia física de la iglesia. Podemos observar cómo en el obispado cordobés el obispo se permitía transgredir las decisiones reales atendiendo a la realidad de su diócesis. Tal es así que el 8 de junio de 1790 el cabildo recibió un oficio del obispo Moscoso, en el que expresaba que frente a la situación delicada por la que estaba pasando la diócesis, le parecía desacertada la decisión del cabildo de acatar la Cedula Real de 1786 mediante la cual se privaba a los curas rectores de la Catedral el "integro percibo de la renta decimal de que se hallaban en posesión desde tiempo inmemorial" ${ }^{24}$. Su opinión se basaba en que sin la renta decimal no quedaba ningún otro ramo fijo con que sustentarse. El prelado recomendaba:

"[...] juzgo muy propio de mi cargo pastoral ocurriendo del perjuicio de otros Curas Rectores prevenir a Vuestra Señoria se sirva diputar un individuo de su cuerpo que haga a nombre mío las más vivas y oportunas instancias representando, que de no ser terminante la Real Orden reservada que tengo noticia se comunico circularmente a los Señores Intendentes para que mantengan las cosas en el estado que tenían al tiempo de su recibo sin innovar en el particular, se ampare a los enunciados curas en la posesión en que se habían, suspendiendo en esta parte el cumplimiento de la citada Real Cedula [... $]^{\prime 25}$

Por este motivo Moscoso recordaba a la feligresía que "[...] satisfagan puntualmente el diezmo de todos los frutos, que recojiesen, y que según costumbre establecimiento y providencia libradas en el asunto deben pagar", y advertía que mediante

${ }^{23}$ AAC, Leg 17, T. I, 13/10/1803.

${ }^{24}$ AAC, Actas Capitulares, Libro 3, 86v.

${ }^{25}$ AAC, Actas Capitulares, Libro 3, 86r. 
"la satisfacción à tan justa deuda no solo lograran coger frutos en abundancia, sino también muchos consuelos y gracias espirituales". Por el contrario, el incumplimiento de esta obligación traería a los deudores "la langosta y el gusano, consumirá las mieses esterilizando las viñas, destruirá los ganados, no regaran las nubes los campos [...]" ${ }^{26}$

La recaudación del diezmo y otros emolumentos eclesiásticos no tenía, para fines del siglo XVIII, la rigurosidad que se necesitaba para poner en orden las necesidades de la diócesis tucumana. En este sentido, Moscoso informaba que:

“[...] ha habido un gravícimo descuido en el zelo, exactitud y pureza, con que deben mirarse estos sagrados intereses [los derechos que se cobran de fabrica sepultura y limosna], que aunque escasos, y cortos son los únicos que hacen el fondo $[i]^{27}$ del que subsisten las iglesias de campaña, y a que por lo tanto deben poner la mayor prolijidad en su Cobro, gastos y apuntamiento sin los que por lo comun resultan confuciones que son perjudiciales a ellas". ${ }^{28}$

Por último, nos parece interesante detenernos en un auto del obispo Moscoso que llamaba la atención respecto del cumplimiento del precepto anual.

De acuerdo a las observaciones del prelado, debía reforzarse el control que los curas debían hacer en Semana Santa sobre su feligresía. Los clérigos debían exhortar a sus fieles, y llevar registro de quiénes habían cumplido con el precepto anual. Éste consistía en la obligación de confesarse y tomar la comunión al menos una vez al año, durante la Pascua. No obstante, según Moscoso, esto no se cumplía en todos los casos ya que muchos sacerdotes "jamás han podido conseguir concurran a este acto otras personas". ${ }^{29}$

Al parecer, sucedía que en ocasiones "muchachos de las Escuelas, y algunas mugeres del baxo pueblo, examinándose muchas veces proveen de cedulas a las demás gentes, y hacen una especie de trafico con ellas [...]". ${ }^{30}$ Esta estrategia de evasión del precepto anual no fue exclusiva de la diócesis tucumana. En el obispado de México en el mismo periodo, se descubrió que "ciertos indios en la ciudad comulgaban dos o tres veces para luego vender sus cedulas adicionales a la gente que no quería confesarse" (Taylor, 1999: 360).

En algunas oportunidades, el incumplimiento de la práctica de confesión anual se relacionaba con una antipatía personal hacia el cura. Ya hemos mencionado las faltas del cura de San Javier descubiertas en la visita celebrada a ese curato en 1803. Como vimos, Albares era acusado por su feligresía de no cumplir con la enseñanza de la

\footnotetext{
${ }^{26}$ AAC, Autos y ordenes generales (1782-1859), Córdoba, 22-06-1795.

${ }^{27}$ Palabra ilegible en el documento.

${ }^{28}$ AAC, Leg. 17, Visita a San Javier, f. 15 v., 26/01/1803.

${ }^{29}$ AAC, Autos y ordenes generales (1782-1859), Córdoba, 10-03-1801.

${ }^{30}$ AAC, Autos y ordenes generales (1782-1859), Córdoba, 10-03-1801.
} 
Mazzoni. La administración diocesana como instrumento de equipamiento eclesiástico del territorio...

doctrina cristiana, de no impartir los sacramentos ni tener ayudante que los impartiera en las capillas de Ambul, Panaholma y Nono alejadas a su residencia, y de fomentar en el púlpito las enemistades entre la feligresía y con el propio sacerdote y los vecinos. Con respecto a este último punto, los fieles se quejaban de que durante las pláticas morales de la misa "ha usado de expresiones satíricas, con que ha bulnerado el honor de sus feligreses, quienes en lugar de salir edificados de la Iglesia, se buelven à sus casas con los animos irritados contra su cura". ${ }^{31}$ Durante esa visita, vecinos notables de la comunidad fueron llamados a testimoniar sobre el accionar del sacerdote. Tres de ellos eran jueces pedáneos de pueblos que pertenecían al curato. Luego de interrogarlos, el visitador informaba al obispo que el cura "con su poca prudencia, y terquedad aterra a los penitentes", y que muchos vecinos notables de la comunidad habían entrado en conflicto porque cobraba derechos excesivos, o por haberlos difamado en conversaciones privadas.

Ante estas denuncias, Moscoso reemplazó a Albares por el Doctor Trucios, notario de la visita, y citó al párroco a la Audiencia Episcopal para indagarlo sobre estos hechos. En Córdoba, Albares respondió que quienes habían faltado al cumplimiento del precepto anual eran precisamente quienes habían sido tomados por testigos por el visitador y habían denunciado al párroco por sus irregularidades en el cumplimiento de la función pastoral:

"los que le nombro a su Señoria Ilustrisima, principales, fueron los tres Jueses de aquel Partido, que fueron Don Angel Terán, Don Mauricio Olmedo que jamás se han confesado hasta ahora, y el otro fue Don Jeronimo Carballo [...] y a todos los ha requerido con sensura y con decirles que era prebencion del Señor Obispo que procederia a declararlos descomulgados, y al exemplo de estos se quedaban sin confesar otros muchos, por que como eran los jueses no tenia con quien hacerlos apremiar." ${ }^{32}$

Finalmente, es importante analizar el hecho mismo de la citación que el obispo cursaba a Albares para que se presentase en la Audiencia Episcopal. En octubre de 1803, Albares llegó a Córdoba, y Moscoso en persona lo recibió, le tomó juramento e interrogó sobre las denuncias levantadas en su contra. El interrogatorio tenía así un carácter misional, porque el obispo intentaba allí corregir mediante la confesión del error y la enseñanza de la doctrina el desempeño del párroco. Pero además, implicaba un símbolo de la función del obispo como juez y arbitro de disputas al interior del obispado, y como fuente de la autoridad jurídica; impartir justicia en este caso representaba otro de los aspectos vinculados con la intención de reforzar el control de la diócesis y mediar entre los fieles y los sacerdotes.

\footnotetext{
${ }^{31}$ AAC, Leg. 17 Visitas Canónicas, 09/02/1803.
}

${ }^{32}$ AAC, Leg. 17, T. I, 26/10/1803. 


\section{Pastoral}

Como hemos visto, la participación de la feligresía en las celebraciones religiosas había sido uno de los puntos de reforma del obispo. Así, el rol activo de los seglares en cofradías, la celebración de bautismos privados, o la tarea de los mayordomos como administradores del templo y de los ornamentos del ceremonial fueron objeto de observación y regulación en las visitas canónicas.

En este sentido, parte de la tarea pastoral de Moscoso se basó en el fomento de la participación de la feligresía en el culto. Al revisar los libros parroquiales del curato de Ischilín en 1796, el obispo arequipeño mandaba "que se entreguen al Patron de la de Copacabana los 74 pesos que resultan a favor de ella, para que con ellos la repare, y ponga en estado, que pueda servir" ${ }^{33} \mathrm{La}$ cita hace referencia a una práctica habitual de la iglesia colonial, y que tenía que ver con el cuidado que los fieles ofrecían a los objetos de culto. Así, el patrón de la imagen de la Virgen de Copacabana era un feligrés de la parroquia encargado de administrar la limosna recogida en nombre de dicha advocación mariana, y de reparar y adornar la imagen para que pudiera exponerse en el templo.

El cuidado de los ornamentos y la parafernalia de la liturgia también eran preocupaciones del obispo. En Ischilín, al revisar los Libros de fábrica, Moscoso ordenaba que con lo recaudado en la parroquia "con los dos pesos 5 reales que resultan a favor de la Capilla de Ischilin, se vista un muchacho, que pueda ayudar à Misa de la que cuidara el expresado cura". ${ }^{34}$

En el espacio cordobés a fines del siglo XVIII y principios del siglo XIX, la iglesia se apoyaba en la feligresía para dar cuerpo al espacio diocesano. Los fieles participaban en las ceremonias, costeaban el ceremonial del culto a través de cofradías, y contribuían con la fábrica de los templos por medio de donaciones y con el diezmo o las mandas pías. Tanto en la visita a Molinos en 1795, como en la hecha al curato de Pocho en 1803, Moscoso subrayaba la labor de los mayordomos, vecinos de la comunidad, en la conservación, aseo y cuidado de la fábrica de los templos. Esto nos permite observar que el gobierno diocesano situaba a algunos fieles en tanto mediadores entre la feligresía y un clero que era escaso, y cuya presencia en algunos curatos no era lo suficientemente palpable (Ayrolo 2011).

Con respecto a los bautismos, esta atribución especial de los fieles solamente podía implementarse -en teoría- en los casos de urgencia. Por ejemplo, en un parto riesgoso la partera o alguna otra persona solía bautizar al recién nacido por el peligro de que muriera sin haber sido bautizado. Esta situación preocupaba a los obispos, quienes intentaban hacer del clero el único intermediario entre los fieles y Dios. De esta manera, el obispo arequipeño prevenía "que los párrocos observen puntualmente lo prevenido por el Ritual Romano en quanto a averiguar si las parteras de su distrito se hallan bien

\footnotetext{
${ }^{33}$ AAC, Leg. 17, Autos de Visita, 04/02/1796.

${ }^{34}$ AAC, Leg. 17, Autos de Visita, 04/02/1796.
} 
Mazzoni. La administración diocesana como instrumento de equipamiento eclesiástico del territorio...

instruidas en el modo y legitima forma de administrar el Bautismo para que no se frustre este sacramento en los casos de urgente necesidad". ${ }^{35}$

Por supuesto que la regulación de la celebración de bautismos privados también fue objeto del control diocesano. Muchas veces la consecución de estas ceremonias no se daba por una cuestión de urgencia o necesidad, sino que proliferaban bautismos celebrados en casas particulares o sin la presencia de un sacerdote o ayudante. Sobre los bautismos, el obispo mandaba:

"[...] de ningún modo hagan semejantes Bautismos privados a no ser que estando enfermo el recien nacido se tema prudentemente muera antes de poderlo conducir a la Iglesia o que con el desabrigo se le agrave el mal, y aun en estos casos los Curas Rectores y sus Ayudantes hagan por si mismos los Bautismos sin dar licencia para ello a otro sacerdote secular o regular." ${ }^{\prime 36}$

Esta era una práctica recurrente entre la feligresía cordobesa. El obispo Abad Illana (quien ocupó la silla episcopal desde 1763 a1770) ya había redactado un auto con fecha 28 de mayo de 1775, en el que establecía la "pena de excomunion mayor y 50 pesos aplicados a la Fabrica de la Iglesia" ${ }^{37}$ a los sacerdotes seculares y regulares que practicaran bautismos privados.

De hecho, en 1798 en la visita al curato de Pocho, Moscoso observaba la continuación de esta práctica, y ordenaba "que en los bautismos privados, y quando solo se ponen los oleos no admita Padrinos, pues en estos casos según las disposiciones de la Iglesia que por justísimos motivos ha querido minorar las coronaciones no son nesesarios, ni en ellos se contrahe el parentesco espiritual" ${ }^{38}$

En el caso de los matrimonios, la costumbre de celebrarlos por fuera del ámbito eclesiástico podía deberse al impedimento de los futuros esposos de contraer matrimonio, sobre todo por lazos de consanguineidad, o por tratarse de periodos en los que no podían celebrarse. En los libros de Casamiento del Curato Rectoral aparecía:

"[...] muchas de las Partidas, que algunos después de estar casados permanecen muchos años sin velarse, y que esto en mucha parte proviene, ò por los Matrimonios que se celebran en los tiempos prohibidos para las relaciones, ò por la facilidad con que los Curas Rectores con una total inobservancia de lo mandado por sus Antecesores bajo de excomunion mayor ipso facto incurrenda delegan a otros simples sacerdotes la facultad de asistir a los Matrimonios en distintas Iglesias o en las casas

\footnotetext{
${ }^{35}$ AAC, Autos y ordenes generales (1782-1859), Salta, 07-03-1792.

${ }^{36}$ AAC, Leg. 17, Visita de la Ciudad de Córdoba y su partido, 20/04/1795.

${ }^{37}$ AAC, Leg. 17, Visita de la Ciudad de Córdoba y su partido, 20/04/1795.

${ }^{38}$ AAC, Leg 17, Visita a los Libros parroquiales del Curato de Pocho, 06/03/1798.
} 


\author{
particulares $[\ldots]^{\prime 39}$
}

Y por otra parte, Moscoso regulaba la jurisdicción de los sacerdotes para juzgar en temas de causas matrimoniales, y les recordaba "una real Cedula por la cual estan autorizados a juzgar en temas de concubinato, y no solo los Jueces Reales tienen competencia en este asunto" ${ }^{40}$ Sobre este punto, la superposición de jurisdicciones con la justicia seglar significó otro punto de contacto en la conflictiva relación entre el Gobernador-intendente y el obispo (Mazzoni 2013; 2015).

\title{
Consideraciones finales
}

La administración de Ángel Mariano Moscoso se rigió por la premisa de conocer para gobernar. Para ello, se abocó a concretar la visita de todo el obispado. El prelado se valió de esta herramienta pastoral como "instrumento de control del territorio y, por consiguiente, de gobierno de la diócesis" (Palomo, 1997: 123). El accionar del obispo puede enmarcarse en el proceso de confesionalización que se había iniciado en la Península en la Edad Moderna, y la necesidad de equipar el territorio en lo que respecta al papel que desempeñaron las instituciones eclesiásticas allí donde el poder político y eclesiástico era débil (Palomo, 1997: 121).

Su preocupación por hacer de los feligreses cristianos idóneos se tradujo en acciones concretas. El obispo celebró numerosas visitas a su diócesis con el fin de controlar las prácticas del clero y la feligresía. Esta actitud marca una diferencia con otras gestiones eclesiásticas. En el caso de su antecesor, San Alberto, por ejemplo, su gobierno se basó mayoritariamente en la producción de escritos que buscaban el mismo fin: la prédica y la enseñanza de la correcta doctrina cristiana. Pero se trataba de un obispo menos presente y pragmático, un teórico (Demélas, 2003: 94).

En el caso del obispo Benito de Lué y Riega, quien ocupó la silla del Obispado de Buenos Aires casi en el mismo periodo que Moscoso (1802 a 1812), la celebración de visitas también fue analizada como un instrumento de intervención eclesiástica, y su política pastoral apuntaba al control social. El gobierno de este prelado, y la celebración de visitas en el espacio rioplatense fueron vistas como claros "esfuerzos por disciplinar tanto el comportamiento de los propios eclesiásticos como el de los feligreses, corrigiendo las manifestaciones desviadas de una religiosidad popular" (Barral y Di Stefano, 1999).

La gestión episcopal, en este sentido, puede ser entendida como un proceso de control social. De esta manera, los aspectos cotidianos regulados a través de la visita se vinculaban con una construcción de poder y de negociación del orden social en el obispado tucumano a fines del periodo colonial. El ejercicio de gobierno, la construcción de poder, en este caso por parte del obispo, responde a una consideración de la política como un terreno intervinculado en el que el poder es disputado, legitimado y redefinido (Mallon, 2002: 106).

\footnotetext{
${ }^{39}$ AAC, Leg. 17, Visita de la Ciudad de Córdoba y su partido, 20/04/1795.

${ }^{40}$ AAC, Leg 17, t. I, Auto sobre Real Cedula Concubinato, 1795.
} 
Mazzoni. La administración diocesana como instrumento de equipamiento eclesiástico del territorio...

La administración de Moscoso implicó un compromiso personal con la tarea de dirigir su obispado. Probablemente, esta actitud estuviera relacionada con su experiencia en el Alto Perú, y con las características propias de las parroquias altoperuanas, en las cuales la mayor cantidad de población y la profusión de la red parroquial (en comparación a las diócesis tucumana y rioplatense), significaban un contacto mucho más frecuente con su feligresía. Y sin duda, esta actitud se relacionaba con su formación: él mismo había sido un cura de parroquia, un párroco rural en San Pedro de Tarata, en permanente contacto con sus fieles, en una relación estrecha de prédica, confesión y acción pastoral que se distanciaba de modelos de sacerdocio más intelectuales, como el de San Alberto (Mazzoni, 2013). A diferencia de su predecesor, Moscoso no había tenido contacto con los círculos intelectuales de la ilustración española en la Corte: su pastoral se traducía en labor de campo, en experimentación, en pragmatismo; en definitiva, en contacto personal y directo con los fieles.

La experiencia episcopal de Moscoso fortaleció la imagen de la autoridad diocesana, haciéndola más presente y tangible, sobre todo en los espacios rurales, donde la presencia de la iglesia era más débil. Su gobierno contribuyó de esta manera al robustecimiento de la identidad territorial, demarcando la presencia de lo sagrado en las zonas rurales del Obispado de Tucumán.

\section{Referencias bibliográficas}

Aparicio O. de M., S. 2000. El clero y la rebelión de Túpac Amaru. Cuzco.

Ayrolo, V. 2011. "Mediadores en "zona de contacto" La acción de los seglares en algunas de las tareas religiosas». En: XVI Jornadas sobre Alternativas Religiosas en América Latina. Punta del Este, Uruguay.

Barral, M. E. 2005. «Parroquias rurales, clero y población en Buenos Aires durante la primera mitad del siglo XIX». Anuario IEHS, Nº 20, pp. 359-88.

Barral, M. E. y Di Stefano, R. 1999. «La diócesis de Buenos Aires a principios del siglo XIX: estructuras eclesiásticas y política pastoral». En: Neuquén.

Barral, M. E. y Fradkin, R. 2007. «Los pueblos y la construcción de las estructuras de poder institucional en la campaña bonaerense (1785-1836)». En: Fradkin, R. (ed.) El poder y la vara. Estudios sobre la justicia y la construcción del estado en el Buenos Aires rural, 1780-1830, Buenos Aires, Prometeo.

Barriera, D. G. 2010. Instituciones, gobierno y territorio. Rosario de la Capilla al Municipio (1725-1930). Rosario, ISHIR-CONICET.

Bourdieu, P. 1985. «Espacio social y espacio simbólico». En: Bourdieu, P. Razones prácticas. Sobre la teoría de la acción, Barcelona, Anagrama.

Bruno, C. 1970. Historia de la Iglesia en la Argentina. Vol. VI. XII. Buenos Aires, Don Bosco.

Christian, W. A. 1991. Religiosidad local en la España de Felipe II. Madrid, Nerea.

Demélas, M.-D. 2003. La invención política. Bolivia, Ecuador, Perú en el siglo XIX. Lima: IFEA, IEP. 
Di Stefano, R. y Zanatta, L. 2009. Historia de la Iglesia Argentina. Desde la conquista hasta fines del Siglo XX. Buenos Aires, Sudamericana.

Mallon, F. 2002. «Reflexiones sobre las ruinas: formas cotidianas de formación del estado en el México decimonónico». En: Gilbert, M. J. y Nugent, D. Aspectos cotidianos de la formación del estado: la revolución y la negociación del mando en el México moderno, Ediciones Era, pp. 105-42.

Martínez de Sánchez, A. M. 2008. «Fuentes de archivo para el estudio del Derecho Canónico Indiano local». Revista de Estudios Histórico-jurídicos XXX: 485-503.

Martini, M. P. 1997. «Perfil jurídico de la visita pastoral. Aportes a su aplicación dentro del actual territorio argentino». En: XI Congreso del Instituto Internacional de Historia del Derecho Indiano. Buenos Aires, Instituto de Investigaciones de Historia del Derecho Indiano.

Mazzoni, M. L. 2013. «Mandato divino y poder terrenal. La administración diocesana en el Obispado de Córdoba, 1778-1836». Tesis doctoral, Tandil, Universidad Nacional del Centro de la Provincia de Buenos Aires.

2015. «La administración diocesana en Córdoba del Tucumán en el periodo tardocolonial en el marco de la legislación eclesiástica de Lima y Charcas». En Nuevos campos de investigación en la historia de las instituciones eclesiásticas y del derecho canónico indiano en el virreinato del Perú (siglos $X V I-X I X)$, Instituto Max Planck para la Historia del Derecho Europeo, en prensa.

Moyano, R. 1893. Origen y coronación de Ntra. Sra. del Rosario del Milagro. 2da. ed. Vol. I. Buenos Aires, P.E. Coni.

Palomo, F. 1997. «"Disciplina christiana”: Apuntes historiográficos en torno a la disciplina y el disciplinamiento social como categorías de la historia religiosa de la alta edad moderna». Cuadernos de historia moderna, $\mathrm{N}^{\circ} 18: 119-38$.

Robins, Nicholas A. 2009. Comunidad, clero y conflicto: las relaciones entre la curia y los indios en al Alto Perú, 1750-1780. La Paz, Plural.

Rojas Ingunza, E. 2007. El báculo y la espada: el obispo Goyeneche y la iglesia ante la iniciación de la República, Perú 1825-1841. Lima, Instituto Riva Agüero.

Taylor, W. 1999. Ministros de lo sagrado. Sacerdotes y feligreses en el México del siglo XVIII. Vol. I. II vols. México, El colegio de México y El colegio de Michoacán. 